\title{
The quality of treatment of hyperacute ischemic stroke in Canada: a retrospective chart audit
}

\author{
Aravind Ganesh MD, Marie Camden MD, Patrice Lindsay RN PhD, Moira K. Kapral MD, \\ Robert Coté MD, Jiming Fang PhD, Brandon Zagorski MSc, Michael Douglas Hill MD MSc; \\ for the Canadian Stroke Audit Group
}

\section{Abstract}

Background: The use of thrombolysis in acute stroke is an important indicator of the quality of stroke care, because it requires health care providers to work collaboratively, rapidly and accurately to optimize patient outcomes. We sought to assess the quality of hyperacute stroke care in Canada using the rate of thrombolysis as the key indicator.

Methods: We used national administrative data and a chart audit in a retrospective cohort design. We identified discharge diagnoses of stroke in the 10 Canadian provinces between 2008 and 2009. We drew a sample (over-weighted by population and hospital size) for a detailed chart review that was focused on identifying indicators of acute stroke care. We determined the proportions of thrombolysis use, complications and outcomes, adjusted for age and sex and stratified by type of hospital.

Results: Our final audit sample included 9588 patient charts, representative of $88 \%$ of the 43651 cases of stroke for which patients were admitted to hospital in Canada. A total of 5.4\% (95\% confidence interval [Cl] 5.1-5.6) of patients with stroke and 6.1\% (95\% Cl 5.8-6.4) of patients with ischemic stroke received thrombolysis. Comprehensive stroke centres used thrombolysis in about one-third of ischemic cases - double the rate seen in primary stroke centres. Often (35\%-49\% of the time), thrombolysis was not given owing to an interval of more than 4.5 hours between stroke onset and arrival at hospital.

Interpretation: The use of thrombolysis for acute stroke in Canada remains low and is limited by delays in both the arrival of patients to hospital and the in-hospital processes of neuroimaging and thrombolysis administration. Our data show the critical need for concerted national efforts to improve education regarding the treatment of acute stroke and speed up stroke management in the hospital setting.

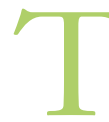
he evidence-to-practice gap in the treatment of acute stroke is thought to be large on a population basis. ${ }^{1}$ Although treatments have evolved rapidly, their uptake and application have been slow and inconsistent. ${ }^{1}$ The use of thrombolysis for acute ischemic stroke is an important quality indicator and is a focal point of international quality-improvement initiatives. ${ }^{2-4}$ The rates of use of acute thrombolysis in the United States, ${ }^{5}$ Ireland, ${ }^{6}$ the United Kingdom ${ }^{7}$ and Sweden ${ }^{8}$ represent too small a fraction of the total number of ischemic strokes.

The use of thrombolysis as an effective treatment for stroke has wrought much system change. Although there is unequivocal evidence for the benefit of timely thrombolysis, ${ }^{9}$ it is a difficult therapy to administer appropriately, in large part because of the tremendous need for speed in application and careful clinical judgment. ${ }^{10}$ Teams of health care providers must work in concert, very rapidly, making the correct decisions to achieve good outcomes. Results from a Finnish prospective registry of consecutive cases of ischemic stroke treated with tissue plasminogen activator and a series of concurrent time-saving interventions implemented in a Helsinki emergency department have shown that very fast treatment is possible, but it is dependent on a well-functioning global system pushing data collection into the prehospital phase and direct linkage of the prehospital and in-hospital response teams. ${ }^{11}$ Previous Canadian data from a national prospective cohort study showed a low rate of thrombolysis and slow treatment times. ${ }^{12}$

We sought to assess the quality of acute stroke care in Canada by conducting a national chart audit. Our key indicator was the rate of thrombolysis in stroke.

Competing interests: See end of article.

Correspondence to: Michael D. Hill, michael.hill@ucalgary.ca

CMAJ Open 2014. DOI:10.9778/cmajo.20140067 


\section{Methods}

\section{Study population}

Participants were selected based on national administrative data from the Canadian Institute for Health Information. All patients with a discharge diagnosis of stroke admitted between Apr. 1, 2008, and Mar. 31, 2009, were eligible for inclusion in the study. The diagnosis of stroke was considered using the following codes from the International Statistical Classification of Diseases and Related Health Problems, 10th Revision (ICD-10): I60, I61, I63, I64, G45. Only the most responsible or first-position diagnosis was considered.

\section{Setting}

Participants were from Canada's 10 provinces. We excluded data from the 3 territories owing to their small populations. Privacy assessments and ethical board reviews were conducted in each province. We drew weighted random samples for detailed chart review for all of the provinces, with the exception of Manitoba. The sample from Manitoba was nonrandom and was drawn from 2 regions that included 7 hospitals at the discretion of the provincial health authority. We excluded cases from hospitals with fewer than 20 admissions for stroke per year. We over-weighted sampling by population and hospital size for smaller provinces and under-represented populations. Thus, our sample is not a simple random sample; it is a weighted sample that is representative of the total burden of stroke in Canada. We classified each hospital as either a "comprehensive stroke centre" or a "primary stroke centre" depending on whether they met the specific criteria for such designations published in the literature (Box 1); ${ }^{13,14}$ we classified hospitals not satisfying these criteria as "other."

\section{Sources of data}

We sourced all administrative data from the Canadian Institute for Health Information and from the Institute of Clinical

Box 1: Characteristics of comprehensive and primary stroke centres $^{13,14}$

\section{Comprehensive stroke centre}

- Advanced thrombolytic capability, including endovascular treatment

- Neurosurgical capability

- Stroke unit care

- Advanced neurovascular imaging capability

- Interdisciplinary stroke team

- Responsibility for stroke service coordination across a region

Primary stroke centre

- Capability to provide acute medical thrombolysis (i.e., intravenous administration of tissue plasminogen activator)

- Stroke unit care

- Interdisciplinary stroke team (but may not be as complete or available as in a comprehensive centre)

- Computed tomography on site

- Responsibility for stroke service within a site
Evaluative Sciences in Ontario. We obtained all chart audit data directly.

\section{Data extraction}

Charts were audited on site by 51 trained chart abstractors. The abstractors received a day-long training session, followed by a supervised onsite day to abstract their first charts. At least 5 charts per abstractor were selected randomly for re-abstraction to check reliability. Each chart was reviewed to obtain patient demographics, prestroke independence, cardiovascular comorbidities, severity of neurologic deficits and indicators of acute stroke care. These indicators included whether or not the patient received thrombolysis, arrival by ambulance, and the time from onset of symptoms and presentation to hospital to receiving a computed tomography (CT) scan or thrombolysis. Outcome indicators were in-hospital death at 7 and 30 days, hemorrhagic transformation and length of stay in hospital. If a patient with acute stroke did not receive thrombolysis, the reasons why were recorded whenever available.

Data were recorded online, stored in a secure central database, anonymized and pooled. We combined the results of an internal Ontario chart audit for the same period (conducted by the Institute for Clinical Evaluative Sciences using the same methods) with those of the current audit of the remaining 9 provinces to yield a national database. We cleaned the data by removing duplicate charts, cases in which more than $30 \%$ of the audit data were missing and cases in which a most responsible diagnosis was not acute stroke or not documented.

\section{Statistical analyses}

We used standard descriptive statistics for all analyses. We applied a statistical weighted adjustment to the audit results based on hospital stroke volumes and the number of charts sampled to avoid potential bias resulting from unequal sampling and to ensure that the results were representative of stroke care across Canada. We adjusted rates for age and sex using the direct method to the 2001 Canadian census. ${ }^{15} \mathrm{We}$ adjusted for comorbidities using the Charlson index stratified into 3 categories $\left(0,1\right.$, or 2 or more comorbid diagnoses).$^{16}$ We reported proportions of thrombolysis use, complications and outcomes stratified by type of hospital.

\section{Results}

We identified 43651 cases of stroke resulting in admission to 624 hospitals during the study period (Table 1). Most of these cases $(87.5 \%)$ were admitted to the 295 hospitals included in our audit (Table 1). Using weighted sampling of the administrative database, the target chart audit sample consisted of 10130 records, of which we recovered 9940 available hospital charts from centres in 10 Canadian provinces. We excluded charts with missing data $(n=142)$ or a clear nonstroke diagnosis $(n=143)$, as well as duplicate records $(n=67)$. Thus, we included 9588 patient charts from 295 hospitals in our audit sample; this is $23.0 \%$ of the admissions for stroke that occurred during the study period, and all of which remained in the final dataset after cleaning. After we applied the weighting 
adjustment, our total audit sample represented 38206 (87.5\%) cases of stroke (33 561 cases of ischemic stroke and 4648 cases of hemorrhagic stroke).

Overall, 5.4\% (95\% confidence interval [C] $5.1 \%-5.6 \%$ ) of patients with stroke in Canada received thrombolysis. Because thrombolysis is contraindicated in hemorrhagic strokes, we also determined the proportion of patients with ischemic stroke who received thrombolysis $(6.1 \%$, 95\% CI 5.8\%-6.4\%; Table 2). Rates by province from the national audit have been previously published. ${ }^{17}$ Comprehensive stroke centres treated about onethird of the ischemic strokes and provided thrombolysis at a rate double that of primary stroke centres $(11.0 \%$ [95\% CI $10.4-$ 11.6] v. 5.7\% [95\% CI 5.2\%-6.2\%]; Table 2). Most patients who received thrombolysis arrived by ambulance, and the mean interval between stroke onset and treatment was 4.2 (standard error [SE] 0.7) hours across all hospitals (Table 3). Of patients who received thrombolysis, $13.6 \%$ died within 30 days and $7.3 \%$ underwent hemorrhagic transformation (Table 4). The mean length of a patient's stay in hospital was 16 [SE 1.6] days (Table 4). The most common reason for not using thrombolysis was an interval between stroke onset and arrival to hospital of more than 4.5 hours $(42.3 \%$, Table 5 ).

\section{Interpretation}

In this retrospective cohort study involving a national chart audit, we used a comprehensive estimate of the total stroke volume in Canada and then carefully reviewed charts to estimate the rate of thrombolysis for acute stroke. Overall thrombolysis rates were low, with higher rates at comprehensive stroke centres, and were most often limited by a delayed presentation to hospital.

\begin{tabular}{|c|c|c|c|c|c|}
\hline \multirow[b]{2}{*}{ Province } & \multicolumn{2}{|c|}{ Total } & \multicolumn{2}{|c|}{ Eligible hospitals only } & \multirow[b]{2}{*}{ Final sample } \\
\hline & No. of hospitals & $\begin{array}{l}\text { No. of } \\
\text { admissions for } \\
\text { stroke }\end{array}$ & No. of hospitals & $\begin{array}{c}\text { No. of } \\
\text { admissions for } \\
\text { stroke }\end{array}$ & \\
\hline $\begin{array}{l}\text { British } \\
\text { Columbia }\end{array}$ & 81 & 5690 & 46 & 5446 & 1198 \\
\hline Alberta & 88 & 3668 & 22 & 3194 & 880 \\
\hline Saskatchewan & 61 & 1787 & 13 & 1385 & 271 \\
\hline Manitoba & 57 & 1633 & 7 & 1030 & 231 \\
\hline Ontario & 145 & 16589 & 103 & 15076 & 2567 \\
\hline Quebec & 101 & 10633 & 66 & 8773 & 1621 \\
\hline New Brunswick & 22 & 1419 & 12 & 1293 & 1007 \\
\hline Nova Scotia & 32 & 1191 & 12 & 1108 & 998 \\
\hline $\begin{array}{l}\text { Prince Edward } \\
\text { Island }\end{array}$ & 7 & 231 & 4 & 239 & 212 \\
\hline $\begin{array}{l}\text { Newfoundland } \\
\text { and Labrador }\end{array}$ & 30 & 810 & 10 & 666 & 603 \\
\hline Totals & 624 & 43651 & 295 & 38210 & 9588 \\
\hline
\end{tabular}

Table 2: Proportion of patients with stroke who presented to Canadian hospitals who received thrombolysis during the study period

\begin{tabular}{|lccc|}
\hline & Unweighted & \multicolumn{2}{c|}{ Weighted sample } \\
\cline { 2 - 4 } Type of stroke, hospital & $n / N$ & $n / N^{*}$ & $\%(95 \% \mathrm{Cl})$ \\
\hline Overall & $480 / 9588$ & $2049 / 38206$ & $5.4(5.1-5.6)$ \\
\hline Ischemic stroke $\dagger$ & $480 / 8464$ & $2049 / 33561$ & $6.1(5.8-6.4)$ \\
\hline Comprehensive stroke centre & $297 / 3175$ & $1364 / 12400$ & $11.0(10.4-11.6)$ \\
\hline Primary stroke centre & $162 / 2869$ & $569 / 10008$ & $5.7(5.2-6.2)$ \\
\hline Other & $21 / 2420$ & $116 / 11153$ & $1.0(0.8-1.2)$ \\
\hline $\begin{array}{l}\text { Note: } \mathrm{Cl}=\text { confidence interval. } \\
\text { *Weighted sample. } \\
\text { †lschemic stroke = all stroke less hemorrhagic stroke types. }\end{array}$ & & \\
\hline
\end{tabular}




\section{OPEN}

Research

The calculation of thrombolysis rates has varied by jurisdiction, and they are therefore difficult to compare across centres and internationally, most often because the denominator (total cases of stroke) is variably estimated. ${ }^{5-8}$ We found that about one-quarter of the patients who did not receive thrombolysis were noted to have neurological deficits that were too mild for treatment, which is similar to data from a 2001 study by Barber and colleagues. ${ }^{18}$ However, about one-third of these patients will have an outcome of death or disability, ${ }^{18,19}$ which suggests that some of these patients could have undergone treatment.

Our results show that a considerable barrier to thrombolysis remains getting patients to the hospital quickly after the onset of symptoms. The interval between onset and arrival for the comprehensive stroke centres was shorter compared with the interval in primary stroke centres, which likely facilitated higher rates of thrombolysis. Yet even at comprehensive stroke centres, where most patients arrived by ambulance and thus presented with a presumed diagnosis of stroke, the mean interval was slightly more than 3 hours. Improving access at this level is challenging for a number of reasons. First, stroke often renders patients incapable of seeking help themselves, leaving bystanders or family members responsible for contacting emergency services. Second, stroke does not uniformly engender a sense of urgency because it does not usually cause pain. ${ }^{20}$ Third, many people do not know how to recognize stroke in another person and to seek help. ${ }^{21}$ Finally, Canada's vast geography limits the speed of access for patients in rural areas.

A more easily remedied barrier to timely thrombolysis is the marked delay in starting in-hospital processes. Mean intervals from arrival to imaging and from imaging to treatment are very long. Current guidelines recommend that all patients receive treatment within 60 minutes of arrival. ${ }^{22}$ For every minute that the middle cerebral artery remains blocked, an estimated 1.9 million neurons and 12 kilometres of axons are destroyed. ${ }^{23}$ Thus, one can argue even 60 minutes is too long a wait, and we have called for a concerted national effort to reduce in-hospital times to 30 minutes or less. ${ }^{24}$ In Helsinki,

Table 3: Clinical and treatment characteristics of Canadian patients presenting with acute ischemic stroke who received thrombolysis during the study period

\begin{tabular}{|c|c|c|c|c|}
\hline \multirow[b]{2}{*}{ Characteristic } & \multicolumn{4}{|c|}{ Proportion of patients, \%* } \\
\hline & $\begin{array}{c}\text { Comprehensive } \\
\text { stroke centre } \\
n=297 \\
N, \text { weighted = } \\
1363.8(66.5 \%)\end{array}$ & $\begin{array}{c}\text { Primary stroke } \\
\text { centre } \\
n=162 \\
N, \text { weighted = } \\
569.4(27.8 \%)\end{array}$ & $\begin{array}{c}\text { Other } n=21 \\
N, \text { weighted }= \\
116.3(5.7 \%)\end{array}$ & $\begin{array}{c}\text { Overall } \\
n=480 \\
N, \text { weighted }= \\
2049.5\end{array}$ \\
\hline Age $\geq 70 \mathrm{yr}$ & 60.2 & 55.1 & 73.9 & 59.5 \\
\hline Female sex & 45.4 & 45.2 & 48.7 & 45.5 \\
\hline Hypertension, \% & 67.0 & 65.2 & 77.3 & 67.1 \\
\hline Atrial fibrillation & 21.4 & 16.7 & 14.1 & 19.7 \\
\hline Diabetes mellitus & 22.0 & 14.3 & 15.1 & 19.4 \\
\hline Previous stroke & 16.1 & 23.2 & 11.5 & 17.8 \\
\hline Coronary artery disease & 31.5 & 15.5 & 67.2 & 29.1 \\
\hline Current smoker & 15.5 & 10.0 & 36.4 & 16.1 \\
\hline $\begin{array}{l}\text { Peripheral vascular } \\
\text { disease }\end{array}$ & 2.4 & 1.3 & 18.1 & 3.0 \\
\hline Prestroke independence & 73.8 & 71.5 & 55.7 & 72.1 \\
\hline CNS score $\leq 8$ & 70.9 & 70.9 & 55.7 & 70.0 \\
\hline Arrival by ambulance & 96.2 & 83.4 & 69.7 & 91.2 \\
\hline \multicolumn{5}{|l|}{ Interval, $h$, mean \pm SE } \\
\hline Onset to arrival & $3.3 \pm 1.1 \dagger$ & $5.1 \pm 0.8 \dagger$ & $32.2 \pm 5.7 \dagger$ & $5.4 \pm 0.8$ \\
\hline Arrival to imaging & $0.7 \pm 0.1$ & $3.4 \pm 2.7$ & 4.4 & $1.5 \pm 0.7$ \\
\hline Onset to treatment & $4.6 \pm 1.1$ & $3.4 \pm 0.3$ & $2.9 \pm 0.1$ & $4.2 \pm 0.7$ \\
\hline \multicolumn{5}{|l|}{ Interval, min, mean \pm SE } \\
\hline Imaging to treatment & $79.0 \pm 8.6$ & $71.9 \pm 4.9$ & 84.4 & $77.2 \pm 6.3$ \\
\hline Arrival to treatment & $138.1 \pm 17.7$ & $100.9 \pm 15.3$ & $112.7 \pm 1.9$ & $121.1 \pm 11.4$ \\
\hline $\begin{array}{l}\text { Note: CAD = coronary artery di } \\
{ }^{*} \text { Unless otherwise stated. } \\
\text { †Statistically significant differen } \\
\text { intervals were not significantly }\end{array}$ & $\begin{array}{l}\text { CNS = Canadian n } \\
\text { ween the } 3 \text { groups }( \\
\text { t. }\end{array}$ & $\begin{array}{l}\text { al scale, SE }=\text { star } \\
\text { Primary centre }\end{array}$ & th comprehens & $p=0.05)$. Other \\
\hline
\end{tabular}


median times of 20 minutes have been shown ${ }^{11}$ — with average Canadian times being 90 minutes (Table 3), we can expect that Canadian patients who receive thrombolysis will fare substantially worse than their Finnish counterparts. Whereas the smaller land area of Finland may facilitate faster transport to hospital compared with the more widely spread populations served in Canada, we should be able to replicate Helsinki's success with arrival to treatment intervals by optimizing inhospital processes. A study in Melbourne recently showed the rapid transferability of the Helsinki thrombolysis model, achieving a 25-minute interval within 8 months of changing protocol. ${ }^{25}$
Improving in-hospital processes is feasible because they are controlled by a relatively small number of people. Canada has made progress in this regard in the last decade. Following the publication of the Canadian Alteplase for Stroke Effectiveness study (CASES), ${ }^{12}$ which provided a framework for the development of acute stroke protocols across Canada, and the first Canadian Stroke Best Practice Recommendations, ${ }^{26}$ which highlighted the need for emergent treatment in cases presenting within 4.5 hours, some Canadian centres have achieved substantial improvement in their arrival to treatment times. ${ }^{27-29}$ Salient differences in study design including the types of centres included prevent a fair comparison between

\begin{tabular}{|c|c|c|c|c|c|}
\hline \multirow[b]{2}{*}{ Outcome } & \multicolumn{5}{|c|}{ Proportion of patients, \%* } \\
\hline & $\begin{array}{c}\text { Comprehensive } \\
\text { stroke centre } \\
n=297 \\
N, \text { weighted }= \\
1363.8(66.5 \%)\end{array}$ & $\begin{array}{c}\text { Primary stroke } \\
\text { centre } \\
n=162 \\
N \text {, weighted = } \\
569.4(27.8 \%)\end{array}$ & $\begin{array}{c}\text { Other } \\
n=21 \\
N, \text { weighted }= \\
116.3(5.7 \%)\end{array}$ & $\begin{array}{c}\text { All hospitals } \\
n=480 \\
N, \text { weighted }= \\
2049.5\end{array}$ & $\begin{array}{c}p \\
\text { value† }\end{array}$ \\
\hline In-hospital death at $7 \mathrm{~d}$ & 7.2 & 8.3 & 5.2 & 7.4 & 0.5 \\
\hline In-hospital death at $30 \mathrm{~d}$ & 13.3 & 15.1 & 10.8 & 13.6 & 0.4 \\
\hline $\begin{array}{l}\text { Hemorrhagic } \\
\text { transformation }\end{array}$ & 8.0 & 7.2 & - & 7.3 & 0.006 \\
\hline $\begin{array}{l}\text { Length of stay, } d \text {, mean } \pm \\
\text { SE }\end{array}$ & $15.7 \pm 1.3$ & $16.7 \pm 4.7$ & $15.7 \pm 2.5$ & $16 \pm 1.6$ & $<1.0$ \\
\hline
\end{tabular}

Table 5: Reasons documented for not giving thrombolysis to patients with ischemic stroke presenting to Canadian hospitals during the study period, by hospital type

\begin{tabular}{|c|c|c|c|c|}
\hline \multirow[b]{2}{*}{ Reasons } & \multicolumn{4}{|c|}{ Proportion of patients, $\%$} \\
\hline & $\begin{array}{c}\text { Comprehensive } \\
\text { stroke centre } \\
n=2878 \\
N \text {, weighted }= \\
11036.8\end{array}$ & $\begin{array}{c}\text { Primary stroke } \\
\text { centre } \\
n=2707 \\
N \text {, weighted = } \\
9439.1\end{array}$ & $\begin{array}{c}\text { Other } \\
n=2399 \\
N, \text { weighted }= \\
11036.6\end{array}$ & $\begin{array}{c}\text { All hospitals } \\
n=7984 \\
N, \text { weighted }= \\
31512.5\end{array}$ \\
\hline $\begin{array}{l}\text { Interval from onset of symptoms to } \\
\text { arrival }>4.5 \mathrm{~h}^{\star}\end{array}$ & 48.8 & 35.3 & 41.6 & 42.3 \\
\hline Neurological deficit judged too mild & 26.6 & 22.0 & 24.3 & 24.4 \\
\hline Neurological deficit judged too severe & 3.4 & 2.7 & 3.5 & 3.2 \\
\hline Clear medical contraindication & 6.6 & 4.3 & 3.4 & 4.8 \\
\hline Delayed decision & 0.2 & 0.3 & 0.3 & 0.3 \\
\hline Documented physician decision & 6.4 & 8.0 & 5.3 & 6.5 \\
\hline Not documented & 20.0 & 29.7 & 26.9 & 25.3 \\
\hline
\end{tabular}


CASES and this audit, but it is worth noting that the median onset to treatment time in CASES was 155 minutes, with an arrival to treatment interval of 85 minutes, compared with mean times of 252 and 121 minutes, respectively, in our audit. This shows the need to translate the successes of selected centres into national strategies targeting treatment times.

\section{Limitations and strengths}

We relied on hospital administrative data to estimate the total number of strokes in Canada. Such data do not capture all strokes that occur in Canada; patients that do not enter the hospital system or are discharged from the emergency department would not be included in this number. However, the nature of stroke is such that cases eligible for thrombolysis would result in admission to hospital in most Canadian jurisdictions. Thus, our denominator for estimating the proportion of patients receiving thrombolysis may be slightly underestimated.

In assessing time to treatment, we did not distinguish between thrombolysis administered intravenously and endovascularly. At selected comprehensive stroke centres, endovascular administration may have been offered later, thereby increasing mean times to treatment.

We used a comprehensive sampling strategy to examine a national and population-based estimate of stroke thrombolysis in Canada. Because all patients who receive thrombolysis in Canada are admitted to hospital, we believe that we have captured a comprehensive numerator for determining the national rate of thrombolysis.

In the 5 years since our audit, 2 key advances in the delivery of stroke care have likely resulted in a higher rate of thrombolysis. First, the number of stroke units across the country has increased, although most Canadians with stroke still receive care on general medical or neurology wards. ${ }^{30}$ Second, the use of "telestroke" technology (i.e., the use of videoconferencing to assess patients remotely, combined with the teleradiological review of brain imaging) has increased, with Alberta and Ontario instituting widespread telemedicine services for hyperacute stroke care and British Columbia running pilot programs. ${ }^{31}$

\section{Conclusion}

A maximal thrombolysis rate is unknown, but an estimated $24 \%$ of stroke patients are eligible for treatment if delays between the onset of symptoms and admission to hospital are avoided. ${ }^{32}$ Decision-making requires careful judgment of the degree of disability and estimation of treatment risk, and such expertise is not readily available at all Canadian hospitals. Whereas comprehensive stroke centres showed higher thrombolysis rates in our study, they only serve about one third of the stroke population. Further, they administered thrombolysis to less than half of the possible ceiling rate, implying that there is considerable room for improvement. Therefore, in addition to training stroke neurologists, an emphasis on the education of physicians regarding acute stroke treatment is critical to optimize both the thrombolysis rate and the speed of treatment. The centralization of stroke systems of care, known to be beneficial, ${ }^{33,34}$ is happening in Canada, with a number of centres achieving Stroke Distinction with Accreditation Canada, ${ }^{35}$ but this has not yet translated into an improvement in the speed of treatment. Ultimately, current wait times represent a persistent and unacceptable gap between evidence and practice and clearly suggest that our systems of care require concerted effort to improve.

\section{References}

1. Demaerschalk BM. Evidence-based clinical practice education in cerebrovascular disease. Stroke 2004;35:392-6.

2. Arling G, Reeves M, Ross J, et al. Estimating and reporting on the quality of inpatient stroke care by veterans health administration medical centers. Circ Cardiovasc Qual Outcomes 2012;5:44-51.

3. Abilleira S, Gallofre M, Ribera A, et al. Quality of in-hospital stroke care according to evidence-based performance measures. Stroke 2009;40:1433-8.

4. Paul CL, Levi C, D'Este C, et al. Thrombolysis implementation in stroke (TIPS): evaluating the effectiveness of a strategy to increase the adoption of best evidence practice - protocol for a cluster randomized controlled trial in acute stroke care. Implement Sci 2014;9:38.

5. Adeoye $\mathrm{O}$, Hornung R, Khatri $\mathrm{P}$, et al. Recombinant tissue-type plasminogen activator use for ischemic stroke in the United States: a doubling of treatment rates over the course of 5 years. Stroke 2011;42:1952-5.

6. Collins DR, O'Neill D, McCormack P. Potential for treatment with thrombolysis in an Irish stroke unit. $\operatorname{Ir}$ Med 7 1999;92:236-8.

7. Rudd AG, Hoffman A, Grant R, et al.; Integrated Working Party for Stroke. Stroke thrombolysis in England, Wales and Northern Ireland: How much do we do and how much do we need? 7 Neurol Neurosurg Psychiatry 2011; 82:14-9.

8. Asplund K, Glader E, Norrving B, et al. Riks-Stroke Collaboration. Effects of extending the time window of thrombolysis to 4.5 hours: observations in the Swedish stroke register (riksstroke). Stroke 2011;42:2492-7.

9. Wardlaw JM, Murray V, Berge E, et al. Recombinant tissue plasminogen activator for acute ischaemic stroke: an updated systematic review and metaanalysis. Lancet 2012;379:2364-72.

10. Eissa A, Krass I, Bajorek B. Barriers to the utilization of thrombolysis for acute ischaemic stroke. 7 Clin Pharm Ther 2012;37:399-409.

11. Meretoja A, Strbian D, Mustanoja S, et al. Reducing in-hospital delay to 20 minutes in stroke thrombolysis. Neurology 2012;79:306-13.

12. Hill MD, Buchan A. CASES Investigators. Thrombolysis for acute ischemic stroke: results of the Canadian alteplase for stroke effectiveness study. CMAJ 2005;172:1307-12.

13. Alberts MJ, Latchaw R, Jagoda A, et al. Revised and updated recommendations for the establishment of primary stroke centers: a summary statement from the Brain Attack coalition. Stroke 2011;42:2651-65.

14. Alberts MJ, Latchaw R, Selman W, et al. Recommendations for comprehensive stroke centers: a consensus statement from the Brain Attack Coalition. Stroke 2005;36:1597-616.

15. Statistics Canada. 2001 Census technical report. Ottawa: Statistics Canada; 2003.

16. Sundararajan V, Henderson T, Perry C, et al. New ICD-10 version of the Charlson comorbidity index predicted in-hospital mortality. 7 Clin Epidemiol 2004;57:1288-94.

17. Lindsay P, Cote R, Hill M, et al. The quality of stroke care in Canada. Ottawa: Canadian Stroke Network; 2011. Available: www.canadianstrokenetwork.ca /wp-content/uploads/2011/06/QoSC-EN1.pdf (accessed 2014 May 22).

18. Barber PA, Zhang J, Demchuk AM, et al. Why are stroke patients excluded from TPA therapy? An analysis of patient eligibility. Neurology 2001;56: 1015-20.

19. Smith EE, Abdullah AR, Petkovska I, et al. Poor outcomes in patients who do not receive intravenous tissue plasminogen activator because of mild or improving ischemic stroke. Stroke 2005;36:2497-9.

20. Langdorf MI, Bearie B, Kazzi A, et al. Patients' vs. physicians' assessments of emergencies: the prudent layperson standard. Cal f Emerg Med 2003;4:75-81.

21. Greenlund KJ, Neff L, Zheng Z, et al. Low public recognition of major stroke symptoms. Am 7 Prev Med 2003;25:315-9.

22. Lindsay $\mathrm{P}$, Bayley $M$, Hellings $\mathrm{C}$, et al. Canadian best practice recommendations for stroke care (updated 2008). CMA7 2008;179:S1-125.

23. Saver JL. Time is brain - quantified. Stroke 2006;37:263-6.

24. Kamal N, Benavente O, Buck B, et al. Good is not good enough: the benchmark stroke door-to-needle time should be 30 minutes. Can 7 Neurol Sci. In press.

25. Meretoja A, Weir L, Ugalde M, et al. Helsinki model cut stroke thrombolysis delays to 25 minutes in Melbourne in only 4 months. Neurology 2013;81: 1071-6.

26. Lindsay $\mathrm{P}$, Bayley $\mathrm{M}, \mathrm{McD}$ onald $\mathrm{A}$, et al. Toward a more effective approach to stroke: Canadian best practice recommendations for stroke care. CMA7 2008; 178:1418-25.

27. Hill MD, Barber P, Demchuk A, et al. Building a "brain attack" team to administer thrombolytic therapy for acute ischemic stroke. CMA7 2000;162: 1589-93. 
28. Ghrooda E, Alcock S, Jackson A. Improvement in thrombolytic therapy administration in acute stroke with feedback. Can 7 Neurol Sci 2012;39: 789-92.

29. Mehdiratta M, Woolfenden A, Chapman K, et al. Reduction in IV t-PA door to needle times using an Acute Stroke Triage Pathway. Can 7 Neurol Sci 2006; 33:214-6.

30. Wiedmann S, Heuschmann P, Hill M. Organized stroke care: Germany and Canada. In: Oxford textbook of stroke and cerebrovascular disorders. Oxford (UK): Oxford University Press; 2014:270-79.

31. Bisby M, Campbell M. Expanding telestroke in Canada. Ottawa: Canadian Stroke Network; 2012.Available: http://otn.ca/sites/default/files/files/Telestroke -Report.pdf (accessed 2014 May 22).

32. Boode B, Welzen V, Franke C, et al. Estimating the number of stroke patients eligible for thrombolytic treatment if delay could be avoided. Cerebrovasc Dis 2007;23:294-8

33. Meretoja A, Roine R, Kaste $M$, et al. Effectiveness of primary and comprehensive stroke centers. PERFECT Stroke: a nationwide observational study from Finland. Stroke 2010;41:1102-7.

34. Foley N, Salter K, Teasell R. Specialized stroke services: a meta-analysis comparing three models of care. Cerebrovasc Dis 2007;23:194-202.

35. Distinction S. Secondary stroke distinction. Ottawa: Accreditation Canada; 2013. Available: www.accreditation.ca/stroke-distinction. (accessed 2014Jan. 12)

Competing interests: Michael Hill was a board member and vice-chair of the board for the Heart \& Stroke Foundation of Alberta, Northwest Territory and Nunavut; he currently serves as the chair of the board for the Heart \& Stroke Foundation of Alberta, Northwest Territory and Nunavut; he was a member of the advisory board for the Institute for Circulatory and Respiratory Health of the Canadian Institutes of Health Research; he serves on the governance board of the Canadian Federation of Neurological Sciences; he was a consultant for the Vernalis Group and
Merck; he has received grant money from Roche Canada; he has received payment for lectures from Roche Canada, Servier Canada and BristolMyers Squibb; he owns stock in Calgary Scientific; he has received salary awards from the Heart \& Stroke Foundation of Alberta, Northwest Territory and Nunavut and Alberta Innovates Health Solution. No other competing interests were declared.

Affiliations: The Calgary Stroke Program (Ganesh, Hill), Department of Clinical Neurosciences, Hotchkiss Brain Institute, University of Calgary, Calgary, Alta.; Centre Hospitalier affilié Universitaire de Québec, Hôpital de l'Enfant-Jésus (Camden), Québec City, Que.; The Heart \& Stroke Foundation of Canada (Lindsay), Ottawa, Ont.; Department of Medicine and the Institute for Clinical Evaluative Sciences (Kapral), University of Toronto, Toronto, Ont.; Department of Neurology (Coté, Zagorski), McGill University, Montréal, Que.; Institute for Clinical Evaluative Sciences (Fang), University of Toronto, Toronto, Ont.

Contributors: Aravind Ganesh and Michael Douglas Hill drafted the manuscript. Patrice Lindsay organized and administered the study. All of the authors contributed to the analysis and interpretation of the data, revised the manuscript critically for important intellectual content and approved the final version submitted for publication.

Funding: The study was funded by the Canadian Stroke Network and the Heart \& Stroke Foundation of Canada.

Supplemental information: For reviewer comments and the original submission of this manuscript, please see www.cmajopen.ca/content/2/4 /E233/suppl/DC1 